\title{
PERFORMANCE CORRECTION FACTORS FOR VAPOR COMPRESSION REFRIGERATION AND HEAT PUMP SYSTEMS TESTED WITH UNCONTROLLED CONDENSER CONDITIONS
}

\begin{abstract}
G. M. Nobre ${ }^{a}$,
A. A. Vasconccelos ${ }^{a}$,

A. O. Cárdenas Gómez

E. P. Bandarra Filho ${ }^{b}$, and J. A. R. Parise ${ }^{a}$

${ }^{a}$ Pontifícia Univ. Católica do Rio de Janeiro

Departamento de Engenharia Mecânica

Rua Marquês de São Vicente, 225, Gávea

CEP. 22451-900, Rio de Janeiro, RJ, Brasil

parise@puc-rio.br

${ }^{\text {b}}$ Universidade Federal de Uberlândia,

Faculdade de Engenharia Mecânica,

Av. João Naves de Ávila, 2121,

CEP. 38400-902, Uberlândia, MG, Brasil
\end{abstract}

Received: July 12, 2017

Revised: August 22, 2017

Accepted: December 26, 2017

Keywords: refrigeration testing standards, heat pump testing standards, vapor compression cycle, correction factors, nanofluid

\section{NOMENCLATURE}

$c_{p} \quad$ specific heat at constant pressure, $\mathrm{kJ} / \mathrm{kgK}$

$c_{v} \quad$ specific heat at constant volume, $\mathrm{kJ} / \mathrm{kgK}$

$f_{i} \quad$ pressure ratio parameter, equation (18)

$h \quad$ specific enthalpy, $\mathrm{kJ} / \mathrm{kg}$

$\hat{h}$ function for specific enthalpy, $\mathrm{kJ} / \mathrm{kg}$

$\hat{h}_{L} \quad$ function for liquid specific enthalpy, $\mathrm{kJ} / \mathrm{kg}$

$\dot{m}$ mass flow rate, $\mathrm{kg} / \mathrm{s}$

$n$ polytropic exponent, -

$N \quad$ compressor rotational speed, $\mathrm{Hz}$

$P \quad$ pressure, $\mathrm{kPa}$

$P_{c d}^{*} \quad$ normalized condensing pressure, $\mathrm{kPa}$

$q$ heat transfer per unit mass of refrigerant, $\mathrm{kJ} / \mathrm{kg}$

$\dot{Q} \quad$ rate of heat transfer, $\mathrm{kW}$

$r$ clearance ratio, -

$R^{2} \quad$ coefficient of determination, -

$S \quad$ specific entropy, $\mathrm{kJ} / \mathrm{kgK}$

$T$ temperature, ${ }^{\circ} \mathrm{C}$

$v \quad$ specific volume, $\mathrm{kJ} / \mathrm{kg}$

$V_{c} \quad$ compressor displaced volume, $\mathrm{m}^{3}$
$\dot{W}_{c p} \quad$ compressor shaft power, $\mathrm{kW}$

\section{Greek symbols}

$\gamma \quad$ specific heat ratio, -

$\Delta T_{s c}$ degree of subcooling, $\mathrm{K}$

$\Delta T_{s h}$ degree of superheat, $\mathrm{K}$

$\xi_{m} \quad$ correction factor for mass flow rate, -

$\xi_{n}$ correction factor for compressor specific enthalpy gain, -

$\xi_{q} \quad$ correction factor for refrigeration effect, -

$\eta_{c p} \quad$ compressor overall efficiency, -

$\theta$ pressure ratio parameter, equation (16), -

\section{Subscripts}

1 evaporator outlet, compressor inlet

2 compressor discharge, condenser inlet

2s isentropic compression discharge

3 condenser outlet, expansion device inlet

4 evaporator inlet, expansion device outlet

cd condenser 


$$
\begin{array}{ll}
\text { ev } & \text { evaporator } \\
\text { sc } & \text { subcooling } \\
\text { sh } & \text { superheat }
\end{array}
$$

\section{Subscripts}

* $\quad$ refer to standardized operating conditions

\section{INTRODUCTION}

The testing of refrigeration and heat pump systems, either in laboratory or in field tests, and depending on the experimental apparatus, may present uncontrollable variables like condensing pressure, degree of subcooling in the liquid line or evaporator degree of superheat, whose variations, along the experimental runs, may end up marring overall results.

The present paper presents mathematical expressions, based on a simple thermodynamic refrigeration model, that correct calculated (or processed) variables, derived from measured (raw) variables that are bound to vary, or oscillate, between experimental runs, and would preferably remain unchanged.

A similar procedure, for example, has been the practice, for a long time, with the testing of internal combustion engines (Giacosa, 2000; Taylor, 1937). As heat engines that operate open to the atmosphere, their performance is largely affected by parameters like atmospheric pressure, as well as ambient temperature and humidity. The difficulty in controlling such variables during tests entails the utilization of correction factor formulae, particularly, for shaft power.

An overview in the literature reveals no refrigeration or heat pump standard (e.g., AHRI, 2007; European Standard, 2007) envisaging performance correction towards standard operating conditions. On the other hand, Vance Payne and Domanski (2006) worked with a Linear-Fit-Based Rating Procedure which has the inherent potential of providing more accurate ratings on heat pumps and air conditioners.

\section{THERMODYNAMIC MODEL}

The correction factors are based on a simple thermodynamic mathematical model for the vapor compression refrigeration cycles. The model will be applied based on the assumption that the variation of the measured variable will be small enough to hold valid, within that range of variation, all the assumptions established for the model. In the present work, expressions will be derived for three correction factors due to variations of one measured variable, the condensing pressure. Its effect on the evaporator capacity and compressor shaft power will be determined.

A simple vapor compression refrigeration cycle, comprising compressor (1-2), condenser (2-3), expansion device (3-4) and evaporator (4-1) will be considered. For the set of measured and calculated variables previously defined, the following assumptions apply.
a) steady-state operation;
b) negligible pressure drop across heat exchangers;

c) negligible exchange of heat between refrigerant and heat exchangers neighborhoods;

d) constant compressor isentropic efficiency;

e) compressor volumetric efficiency only dependent on the re-expansion of the high pressure gas trapped in the clearance volume, with all other losses having a fixed reduction on the volumetric efficiency;

f) the polytropic exponent remains constant thoughout the experiment;

g) compressor overall efficiency is a function of shaft speed only; device.

h) isenthalpic expansion through the expansion

It should be noted that assumptions (b) to (g) need to be valid only within the small range of variation of the measured and calculated variables. The refrigerant effect, $q_{e v}$, and the refrigeration capacity of the cycle, $\dot{Q}_{e v}$, are given by, respectively:

$$
\begin{gathered}
q_{e v}=\left(h_{1}-h_{4}\right) \\
\dot{Q}_{e v}=\dot{m}\left(h_{1}-h_{4}\right)
\end{gathered}
$$

where $h_{4}$ and $\dot{m}$ are the refrigerant specific enthalpies at inlet and outet of the evaporator, respectively. The refrigerant mass flow rate, $\dot{m}$, is:

$$
\dot{m}=\frac{V_{c}}{v_{1}} N\left\{1-r\left[\left(\frac{P_{c d}}{P_{e v}}\right)^{\frac{1}{n}}-1\right]\right\} C_{v}
$$

where $P_{c d}$ and $P_{e v}$ are condensing and evaporating pressures, respectively; compressor geometry is defined by the displacement volume, $V_{c}$, and clearance ratio, $r$; compressor operational conditions, by rotational speed, $N$, volumetric coefficient, $C_{v}$, which takes into account all other flow losses within the compressor, the polytropic exponent, $n$, and $v_{1}$, the refrigerant specific volume at compressor suction. Likewise, the enthalpy gain during polytropic compression, $\left(h_{2}-h_{1}\right)$, is: 


$$
\frac{\left(h_{2}-h_{1}\right)}{\left(h_{2 s}-h_{1}\right)}=\left(\frac{\frac{n}{n-1}}{\gamma}\right)\left\{\frac{\left[\left(\frac{P_{c d}}{P_{e v}}\right)^{\frac{n-1}{n}}-1\right]}{\left[\left(\frac{P_{c d}}{P_{e v}}\right)^{\frac{\gamma-1}{\gamma}}-1\right]}\right\}
$$

where $h_{2 s}$ is the specific enthalpy of refrigerant at the discharge of an isentropic compression and $\gamma$, the specific heat ratio.

$$
\begin{gathered}
h_{2 s}=\hat{h}\left(s=s_{1} ; P=P_{c d}\right) \\
\gamma=\frac{c_{p}}{c_{v}}
\end{gathered}
$$

Compressor shaft power, $\dot{W}_{c p}$, is calculated in terms of refrigerant mass flow rate, specific enthalpy increase and overall compressor efficiency, $\eta_{c p}$ :

$$
\dot{W}_{c p}=\frac{\dot{m}\left(h_{2}-h_{1}\right)}{\eta_{c p}}
$$
$T_{1}$, is:

Refrigerant temperature at the evaporator outlet,

$$
T_{1}=T_{e v}+\Delta T_{s h}
$$

where $\Delta T_{s h}$ is the evaporator degree of superheat and $T_{e v}$ is the evaporating pressure. From assumption (g), the specific enthalpies at both inlet and outlet of the expansion device, $h_{3}$ and $h_{4}$, respectively, are equal.

$$
\begin{gathered}
h_{4}=h_{3} \\
T_{3}=T_{c d}-\Delta T_{s c}
\end{gathered}
$$

where $T_{c d}$ is the condensing temperature and $\Delta T_{s c}$, the degree of subcooling. Therefore,

$$
h_{3}=\hat{h}_{L}\left(T_{c d}-\Delta T_{s c}\right)
$$

where $h_{3}$ is the specific enthalpy of the liquid at the condenser outlet and $\hat{h}_{L}$ is the liquid specific enthalpy equation, which is, approximately, a function of the temperature only.

\section{CORRECTION FACTORS}

According to the thmodynamic model above, a vapor compression system, working at a condensing pressure $P_{c d}^{*}$ different from that actually measured, $P_{c d}$, for a given experimental run, will imply new values for mass flow rate, $\dot{m}^{*}$, and compressor discharge and condenser outlet specific enthalpies, $h_{2}^{*}$ and $h_{3}^{*}$, respectively.

$$
\begin{gathered}
\dot{m}^{*}=\frac{V_{c}}{v_{1}} N\left\{1-r\left[\left(\frac{P_{c d}^{*}}{P_{e v}}\right)^{\frac{1}{n}}-1\right]\right\} C_{v} \\
h_{3}^{*}=\hat{h}_{L}\left(T_{c d}^{*}-\Delta T_{s c}\right)
\end{gathered}
$$

Consequently, new values for refrigeration capacity and compressor power consumption, are calculated as follows:

$$
\begin{gathered}
\dot{Q}_{e v}^{*}=\dot{m}^{*} q_{e v}^{*}=\dot{m}^{*}\left(h_{1}-h_{3}^{*}\right) \\
\dot{W}_{c p}^{*}=\frac{\dot{m}^{*}\left(h_{2}^{*}-h_{1}\right)}{\eta_{c p}^{*}}
\end{gathered}
$$

Correction factors for refrigerant mass flow rate, refrigeration effect and compressor specific enthalpy gain, $\xi_{m}, \xi_{q}$ and $\xi_{n}$, respectively, can be derived from the model, Eqs. (1) to (11), and Eqs. (12) to (15), above.

$$
\xi_{m}=\frac{\dot{m}^{*}}{\dot{m}}=\frac{\left(1-r \theta^{*}\right)}{(1-r \theta)}
$$

where

$$
\begin{gathered}
\theta=\left[\left(\frac{P_{c d}}{P_{e v}}\right)^{\frac{1}{n}}-1\right] \text { and } \theta^{*}=\left[\left(\frac{P_{c d}^{*}}{P_{e v}}\right)^{\frac{1}{n}}-1\right] \\
\xi_{q}=\frac{q_{e v}^{*}}{q_{e v}}=\frac{\left[h_{1}-\hat{h}_{L}\left(T_{c d}^{*}-\Delta T_{s c}\right)\right]}{\left[h_{1}-\hat{h}_{L}\left(T_{c d}-\Delta T_{s c}\right)\right]} \\
\xi_{n}=\frac{(\Delta h)_{c p}^{*}}{(\Delta h)_{c p}}=\frac{\left(h_{2 s}^{*}-h_{1}\right)}{\left(h_{2 s}-h_{1}\right)} \frac{f_{n}^{*}}{f_{\gamma}^{*}} \frac{f_{\gamma}}{f_{n}}
\end{gathered}
$$


where

$$
\begin{aligned}
& f_{n}^{*}=\left[\left(\frac{P_{c d}^{*}}{P_{e v}}\right)^{\frac{n-1}{n}}-1\right] ; f_{\gamma}^{*}=\left[\left(\frac{P_{c d}^{*}}{P_{e v}}\right)^{\frac{\gamma-1}{\gamma}}-1\right] ; \\
& f_{\gamma}=\left[\left(\frac{P_{c d}}{P_{e v}}\right)^{\frac{\gamma-1}{\gamma}}-1\right] ; f_{n}=\left[\left(\frac{P_{c d}}{P_{e v}}\right)^{\frac{n-1}{n}}-1\right] .
\end{aligned}
$$

\section{VALIDATION OF THE METHOD}

The methodology was tested against experimental data where condensing and evaporating pressures were the controlled variables (Parise and Cartwright, 1988). A reciprocating, twin-cylinder, air-cooled, $25 / 8$ in. $\times 2 \frac{1}{2}$ in., open compressor was driven by a diesel engine. Condenser was watercooled, of the shell-and-coil type, and evaporator, dry-expansion, shell-and-coil type. The expansion device was a thermostatic expansion valve and refrigerant, $\mathrm{CFC} 12$. Condensing temperatures were nominally set at $30^{\circ} \mathrm{C}, 40^{\circ} \mathrm{C}$ and $50^{\circ} \mathrm{C}$. The temperature of $40^{\circ} \mathrm{C}$, and its corresponding saturation pressure, was set as the standard condition. Then, experimental data from all runs were converted to $40^{\circ} \mathrm{C}$ condition, following the method outlined above. Figure 1 shows the variation of the refrigeration capacity, Eq. (2), from the original data, showing distinct curves for each one of the condensing temperatures, $30^{\circ} \mathrm{C}, 40^{\circ} \mathrm{C}$ and $50^{\circ} \mathrm{C}$. Refrigeration capacity was divided by compressor speed, as this parameter was also made to vary in the original data. Application of the parameter correction methodology resulted in a single group of points, Fig. 2. The straight lines in Figs. 1 and 2 are the linear fits of the correspondent data. The coefficients of determination (Di Bucchianico, 2008), $R^{2}$, for the $30^{\circ} \mathrm{C}, 40^{\circ} \mathrm{C}$ and $50^{\circ} \mathrm{C}$ curves in Fig. 1 were, respectively, 0.9449, 0.9764 and 0.9917 , whereas for the whole amount of points, seen as a single group, Fig. 2, corrected to a reference condensing temperature of $40^{\circ} \mathrm{C}$, resulted in 0.9711. It can be seen that, by grouping the experimental data under a single standard condensing pressure, did not affect adversely the scattering of the points, in spite of the relatively high lattitude of the conversions $\left( \pm 10^{\circ} \mathrm{C}\right)$.

Figure 3 shows the variation of the product of mass flow rate and refrigeration effect, wich provides the correction for the refrigeration capacity. It can be seen that corrections ranged within $\pm 10 \%$. Results are also shown for the correction of the enthalpy gain in the compressor, Figs, 4 and 5. The coefficients of determination, $R^{2}$, for the $30^{\circ} \mathrm{C}, 40^{\circ} \mathrm{C}$ and $50^{\circ} \mathrm{C}$ curves in Fig. 4 were, respectively, $0.9263,0.8592$ and 0.8479 , and, with all cases corrected to a condensing temperature of $40^{\circ} \mathrm{C}, 0.9355$.

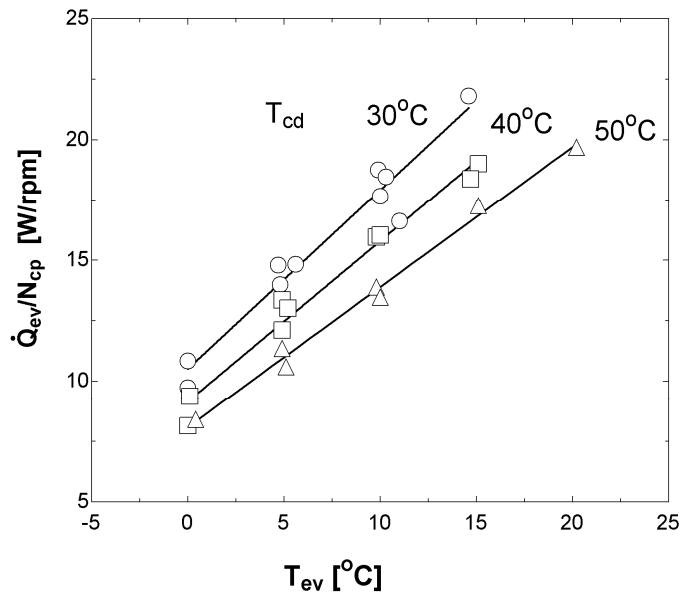

Figure 1. Refrigeration capacity per compressor speed as a function of evaporating and condensing temperatures (Parise and Cartwright, 1988).

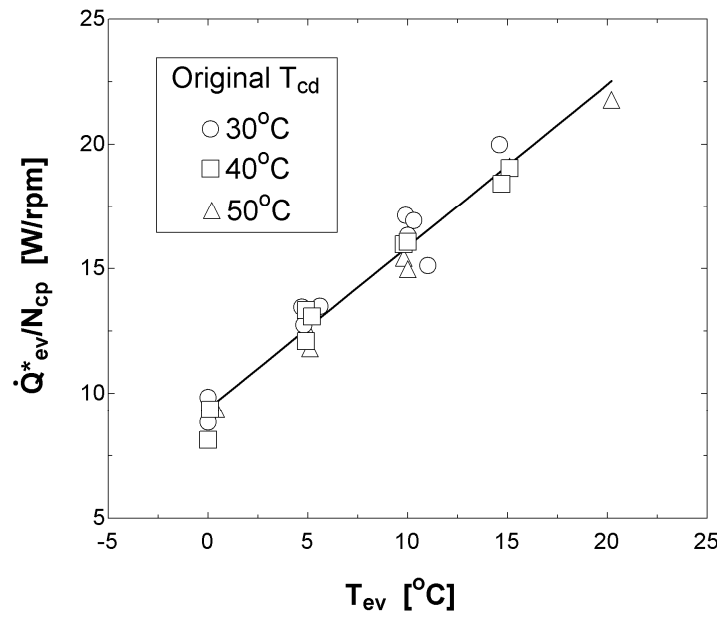

Figure 2. Refrigeration capacity per compressor speed as a function of evaporating, for an standardized condensing temperature of $40^{\circ} \mathrm{C}$.

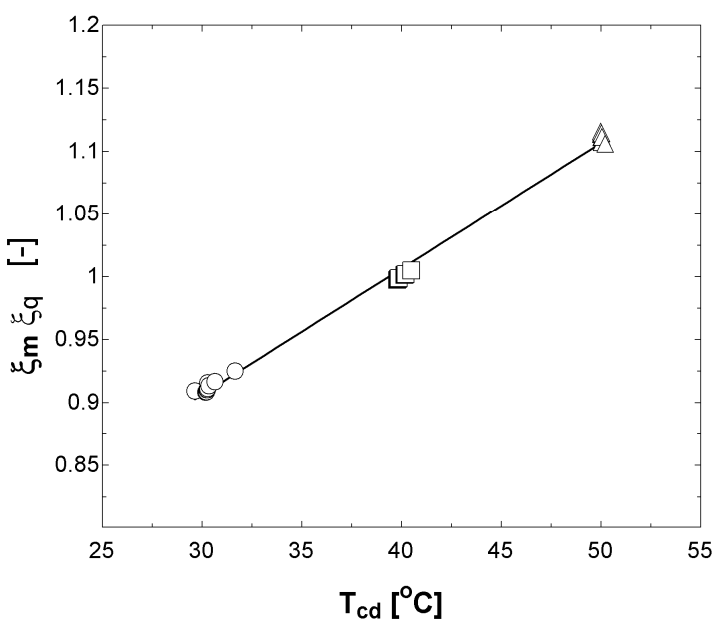

Figure 3. Variation of the refrigeraton capacity correction factor with the condensing temperature. Legend as in Figure 2. 


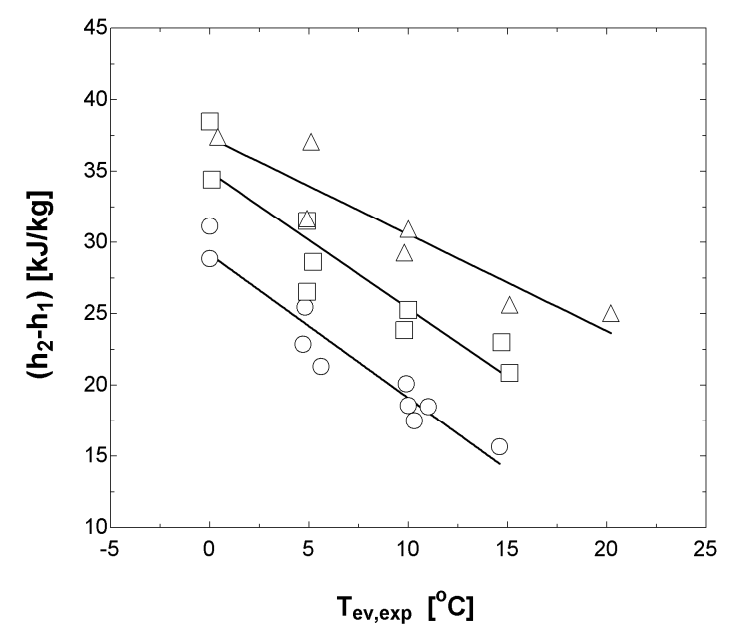

Figure 4. Compressor specific enthalpy gain as a function of evaporating and condensing temperatures (Parise and Cartwright, 1988). Legend as in Figure 2.

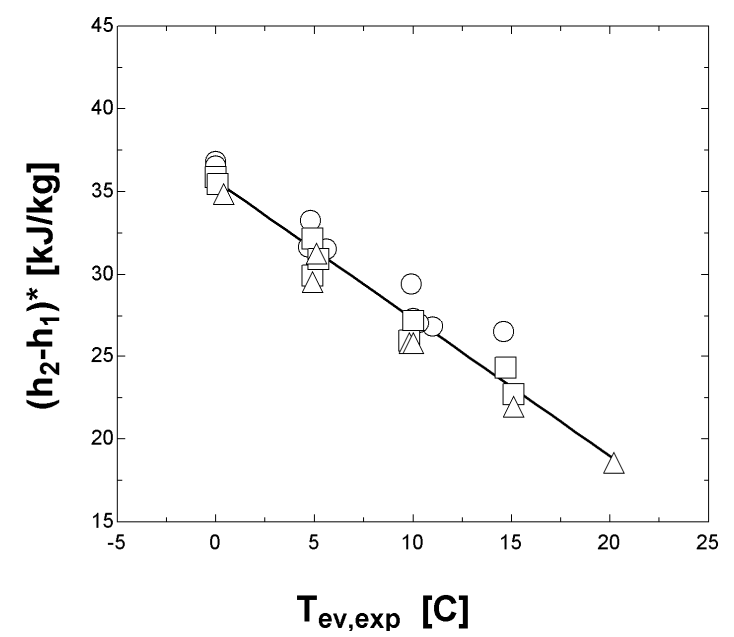

Figure 5. Compressor specific enthalpy gain as a function of evaporating, for an standardized condensing temperature of $40^{\circ} \mathrm{C}$. Legend as in Figure 2.

\section{APPLICATION OF THE METHODOLOGY}

The method was applied to a set of experimental data of a vapor-compression HCFC22 refrigeration system. Water-SWCNT (single walled carbon nano tube) nanofluid was tested as a secondary fluid for the 4-10 $\mathrm{kW}$ indirect vapour compression refrigeration system. The evaporator, with boiling refrigerant exchanging heat with the nanofluid, was of the brazed plate counter-flow type. A semihermetic compressor, an electronic expansion valve (EEV) and an air-cooled condenser were also the main components of the refrigeration cycle.

Figure 6 shows the refrigeration capacity of a system with the secondary fluid (that flows through the evaporator), versus the evaporating temperature. Incidentally, one observes the superior capacity of the system operating with nanofluid, as a results of their enhanced thermal conductivity. Figure 7 depicts the same data with the refrigeration capacity now corrected by the method outlined in the present work. Comparison between graphs in Figs. 6 and 7 show subtle differences between original and corrected data points. This is expected, as the variation the the measured condensing pressure data points is not excessive, allowing for a choice of the reference condensing pressure relatively close to most of the runs). Neverthheless, Fig.7, with corrected points of the refrigeration capacity versus secondary fluid, depicts a smoother distribution of the points.

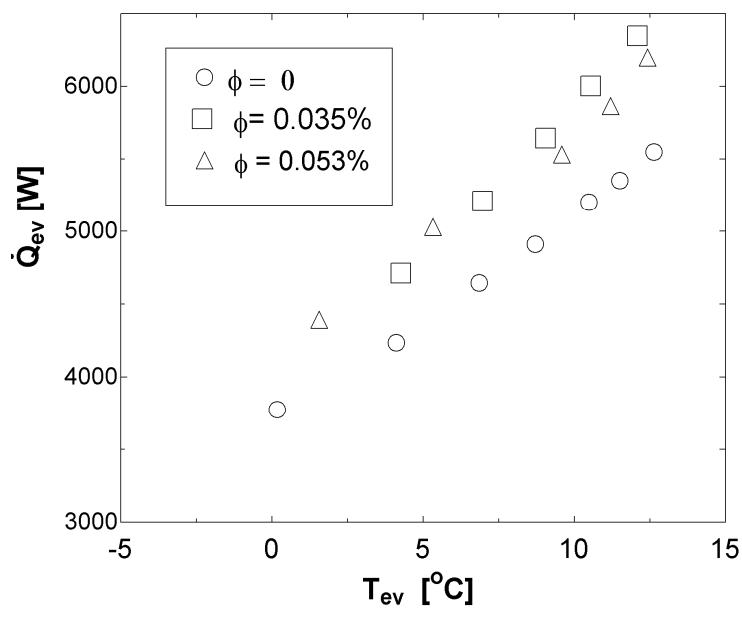

Figure 6. Variation of refrigeration capacity with evaporating temperature, for pure water and waterSWCNT nanofluid at two fractions.

\section{CONCLUSIONS}

A method was devised for the correction of refrigeration cycle performance results in experiments where condenser parameters are not controlled. The method is based on a simple thermodynamic model of the vapour compresion cycle. It was verified against data from a set of CFC12 experiments where evaporating and condensing temperatures were the main controlling parameters. In spite of the large differences between standard and actual condensing pressures, results were encouraging, with a single curve compentently representing all points avialable in the set. The method was, then, applied to a set of experimental data of a vapor-compression $\mathrm{HCFC} 22$ refrigeration system with water or water-SWCNT nanofluid acting as the secondary fluid. It is felt that the smoothness of the data points improved, in comparison with original data.

The method herewith outlined may prove helpful to the researcher or engineer involved with uncontrolled parameters. This method could, of course, be extrapolated to other components of the vapour compression cycle, for both refrigeration and air conditioning or heat pump systems. 


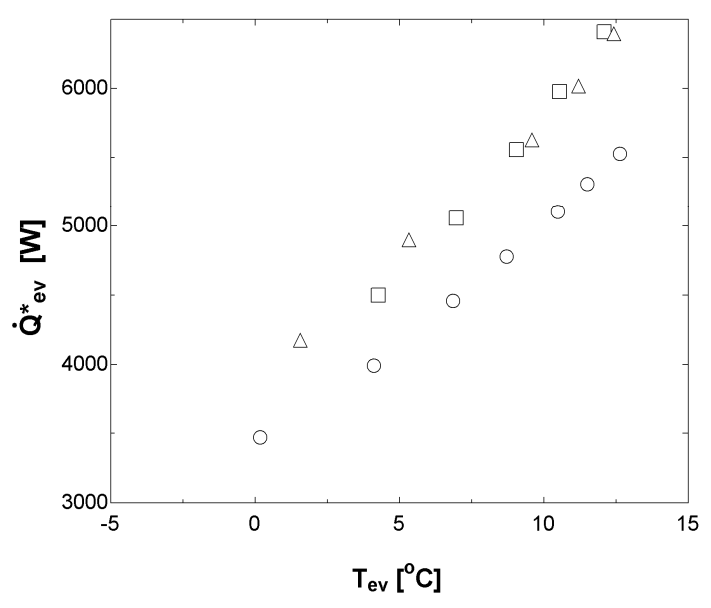

Figure 7. Variation of corrected refrigeration capacity with evaporating temperature, for pure water and water-SWCNT nanofluid at two fractions. Legend as in Figure 6.

\section{ACKNOWLEDGEMENTS}

Authors are indebted to CAPES, CNPq, FAPERJ and FAPEMIG for the finantial support provided. The present work is an extended version of a previous paper, by the same authors (Vasconcelos et al., 2016), presented at the MERCOFRIO 2016, $10^{\circ}$ Congresso Internacional de $\mathrm{Ar}$ Condicionado, Refrigeração, Aquecimento e Ventilação.

\section{REFERENCES}

AHRI, 2007, Standard for Performance Rating of Water-Cooled Refrigerant Condensers, Remote Type, Air-Conditioning, Heating, and Refrigeration Institute.

Di Bucchianico, A., 2008, Coefficient of Determination $\left(\mathrm{R}^{2}\right)$, Encyclopedia of Statistics in Quality and Reliability, Standard Article, Published DOI: 10.1002/9780470061572.eqr173.

European Standard, 2007, EN 14511-2, Air Conditioners, Liquid Chilling Packages and Heat Pumps with Electrically Driven Compressors for Space Heating and Cooling - Part 2: Test Conditions.

Giacosa, D., 2000, Motori Endotermici, Quindicesima Edizione, Editore HOEPLI.

Parise, J. A. R., and Cartwright, W. G., 1988, Experimental Analysis of a Diesel Engine Driven Water-to-Water Heat Pump, Heat Recovery Systems \& ClIP, Vol. 8, No. 2, pp. 75-85.

Vance Payne, W., and Domanski, P. A., 2006, LinearFit-Based Rating Procedure for Mixed AirSource Unitary Air Conditioners and Heat Pumps Operating in the Cooling Mode, NISTIR-7325, National Institute of Standards and Technology, Building Environment Division, Building and Fire Research Laboratory, Gaithersburg, Maryland 208998631, USA.

Vasconcelos, A. A., Cárdenas Gómez, A. O., Bandarra Filho, E. P., and Parise, J. A. R., 2017,
Experimental Evaluation of Water-SWCNT Nanofluid as a Secondary Fluid in a Refrigeration System, also Applied Thermal Engineering, Vol. 111, pp. 1487-1492.

Vasconcelos, A. A., Cárdenas Gómez, A. O., Bandarra Filho, E. P., and Parise, J. A. R., 2016, Performance Correction Factors for Refrigeration and Heat Pump Systems Tested with Uncontrolled Condenser Conditions, in: MERCOFRIO 2016 - $10^{\circ}$ Congresso Internacional de Ar Condicionado, Refrigeração, Aquecimento e Ventilação, Porto Alegre, RS.

Taylor, C. F., 1937, Correcting Diesel Performance to Standard Atmospheric Conditions, SAE Transactions. 